\title{
Quantitative dysmorphology assessment in Fabry disease
}

Markus Ries, MD, MHSc ${ }^{1}$, David F. Moore, MD, PhD ${ }^{2}$, Chevalia J. Robinson, RN, BSN, ${ }^{1}$ Cynthia J. Tifft, MD, PhD ${ }^{3}$, Kenneth N. Rosenbaum, $M D^{3}$, Roscoe O. Brady, MD, ${ }^{1}$ Raphael Schiffmann, MD, ${ }^{1}$ and Donna Krasnewich, $\mathrm{MD}, \mathrm{PhD}^{4}$

\begin{abstract}
Purpose: 1) To identify morphometric characteristics in hemizygous patients with Fabry disease a treatable lysosomal storage disorder caused by the deficiency of $\alpha$-galactosidase A where morphological abnormalities have occasionally been mentioned, but have never been investigated systematically. 2) To devise a quantitative method to evaluate dysmorphic abnormalities in Fabry disease. Method: Cross-sectional, single center, independent dysmorphology assessment by a panel of three clinical geneticists, based on standardized medical photography. Population: consecutive hemizygous patients with Fabry disease $(N=38)$ unselected for the features assessed, mean age $38 \pm 10.8$ years (range: $10-60$ ), recruited for neuropathic pain into enzyme replacement therapy trials. Results: The following dysmorphic features were identified (in order of descending frequency): periorbital fullness, prominent lobules of the ears, bushy eyebrows, recessed forehead, pronounced nasal angle, generous nose/ bulbous nasal tip, prominent supraorbital ridges, shallow midface, full lips, prominent nasal bridge, broad alar base, coarse features, posteriorly rotated ears, and prognathism. Extremity features included broad fingertips, short fingers, prominent superficial vessels of hands, $5^{\text {th }}$ digit brachydactyly, and $5^{\text {th }}$ digit clinodactyly. Narrow anterior-posterior chest diameter was noted. Ten core features were statistically defined. Cronbach's alpha measuring internal consitency was 0.62 . Light's kappa for global inter-rater variability was 0.26 while Cohen's kappa allowing pair-wise rater comparison varied between 0.08-0.48. Conclusions: Patients with Fabry disease share common morphological characteristics of the face, trunk, and extremities. Some of these features are subtle as documented by the inter-rater variability. Awareness of these features may facilitate the diagnosis of patients with Fabry disease, and identification of affected family members. Genet Med 2006:8(2):96-101.
\end{abstract}

Key Words: Fabry Disease/*genetics, dysmorphology, X-linked, diagnosis, enzyme therapy

Fabry disease (FD; OMIM 301500) was first described in independent simultaneous case reports by Fabry ${ }^{1}$ in Germany and Anderson ${ }^{2}$ in the United Kingdom in 1898. The biochemical etiology of the condition, partial or complete deficiency of ceramidtrihexosidase, also referred to as $\alpha$-galactosidase A (GALA) was discovered in 1967. ${ }^{3}$ The gene is located Xq22.1.

In patients with Fabry disease, an accumulation of glycosphingolipids including globotriaosylceramide $\left(\mathrm{Gb}_{3}\right)$, galabiosylceramide, blood group B, B1, and P1 glycolipids occurs in dorsal root ganglia, neuronal cells of the autonomic nervous

From the ${ }^{1}$ Developmental and Metabolic Neurology Branch, National Institute of Neurological Disorders and Stroke, National Institutes of Health, Bethesda, MD; ${ }^{2}$ Section of Neurology, Department of Internal Medicine, University of Manitoba, Canada; ${ }^{3}$ Division of Genetics, Metabolism, and Center for Prenatal Evaluation, Children's National Medical Center, Washington DC; ${ }^{4}$ Medical Genetics Branch, National Human Genome Research Institute, National Institutes of Health, Bethesda, MD.

Markus Ries, MD, MHSc, Developmental and Metabolic Neurology Branch, National Institute of Neurological Disorders and Stroke, National Institutes of Health, 9000 Rockville Pike, Room 3D03, Bethesda, MD 20892-1260.

Submitted for publication August 8, 2005.

Accepted for publication October 5, 2005.

DOI: 10.1097/01.gim.0000200950.25118.dd system, podocytes, tubular epithelial cells, mesangial cells in the kidney, myocardial cells, valvular fibroblasts as well as endothelial cells, pericytes, and smooth muscle of the vascular system. ${ }^{4-10}$ As a result, the nervous system, skin, heart, kidneys and the eyes are affected in this progressive multi-system disorder. FD typically manifests in childhood with hypohidrosis and recurrent episodes of neuropathic pain in the extremities. ${ }^{11,12}$ Disease complications in adulthood include heart failure, ${ }^{13}$ renal impairment, ${ }^{14}$ and cerebrovascular accidents. ${ }^{15}$ There is an enzyme therapy available to treat this condition. ${ }^{16-20}$

Despite clinical sequela appearing in childhood, ${ }^{11,12}$ the diagnosis of Fabry disease is often made late in the course of the disease. For example, the mean age of diagnosis in a cohort of 98 male patients was recently reported to be 21.9 years. ${ }^{21}$ The diagnostic suspicion is sometimes difficult, because patients with Fabry disease present with nonspecific complaints often seen in the general population, such as headaches, abdominal pain, diarrhea, and the definitive diagnosis is often only made when severe disease complications, e.g., stroke, heart and kidney failure, have already occurred. The diagnosis, facilitated by pedigree analysis, is confirmed by GALA enzyme assay and/or mutation analysis. 
In a study conducted by MacDermot, $56 \%$ of 41 hemizygous patients were reported as having a dysmorphic face..$^{21}$ Whybra described a characteristic facial appearance in patients with Fabry disease. ${ }^{22}$ However, these abnormalities have not been precisely defined or validated by a panel of geneticists. Recognition of affected individuals by their facial features would facilitate their identification and ensure timely therapy.

The two objectives in the present study were: 1) to systematically and comprehensively describe the facial, truncal and extremity morphometric characteristics of classically affected hemizygous Fabry disease patients and 2) to evaluate internal consistency and inter-rater variability of these ascribed items and to statistically extract the core features.

\section{PATIENTS AND METHODS}

Thirty-eight male patients out of 35 families with Fabry disease participating in a long-term study of enzyme replacement therapy were evaluated at the National Institutes of Health Clinical Center on a research protocol approved by the Institutional Review Board. Four patients out of two families were brothers; two patients out of one family were cousins. All FD subjects had neuropathic pain and residual GALA activity below $10 \%$ of normal and patients were not selected for morphological abnormalities. Written informed consent was obtained for evaluation, photo documentation, and publication. All thirty-eight were Caucasians; 2 of them were of Hispanic, and 36 of non-Hispanic ethnicity. The patients' ages ranged between 10 to 60 years (mean $38 \pm 10.8$ ). GALA activity and mutation analysis were determined to confirm the diagnosis as previously described. ${ }^{14}$

\section{Photography}

Comprehensive photo documentation was undertaken by the Medical Arts and Photography Branch of the National Institutes of Health according to the principles summarized by Nayler concerning standardization of viewpoint, positioning, lightning, color, magnification, perspective, contrast, background, and image processing. ${ }^{23}$ These standardized views included frontal and lateral views of the head.

\section{Dysmorphic evaluation}

Twenty minor physical variations were assessed on each patient. These included: periorbital fullness, prominent lobules of the ears, bushy eyebrows, recession of the forehead, pronounced nasal angle, broad fingertips, generous nose/bulbous nasal tip, prominent supraorbital ridges, shallow midface, full lips, prominent nasal bridge, broad alar base, coarse facial features, posteriorly rotated ears, and prognathism. Extremity features include short fingers, prominent superficial vessels of hands, $5^{\text {th }}$ digit brachydactyly, and $5^{\text {th }}$ digit clinodactyly. AP diameter of the chest was also assessed from a separate set of photos.

Most features are self-explanatory and consistent with the principles and terminology of dysmorphology. Recession of the forehead was collectively defined as lack of frontal promi- nence. Pronounced nasal angle was defined as the presence of an acute angle between the intersection of the nasal bridge and the nasal root.

\section{Interpretation}

We assembled a panel of three independent geneticists experienced in the evaluation of dysmorphologic features (DK, CT, KR). In a first analysis, a randomly chosen sample of images was analyzed by one member of the panel to define salient features (DK). Then, the images were transmitted to the other two members of the panel for an initial evaluation and feedback concerning the appropriateness of the initial criteria. Having taken these comments into account all images were evaluated independently by all three raters. We chose not to take a consensus approach in order to increase the transparency of the analysis. This is reflected by the inter-rater-variability.

\section{Statistics}

Methods of descriptive statistics were applied. For the table analysis, the median of each item independently assessed by the three raters was calculated. Valid percentages (not includ-

\section{Table 1}

Prevalence of morphometric findings in a cohort of 38 hemizygous patients with Fabry disease

\begin{tabular}{|c|c|c|c|}
\hline Physical features & Present & Absent & I \\
\hline Periorbital fullness ${ }^{a}$ & $87 \%$ & $13 \%$ & 38 \\
\hline Prominent lobules of the ears & $68 \%$ & $32 \%$ & \\
\hline Bushy eyebrows $^{a}$ & $66 \%$ & $34 \%$ & \\
\hline Acute nasal angle ${ }^{a}$ & $61 \%$ & $39 \%$ & \\
\hline Shallow midface & $61 \%$ & $39 \%$ & \\
\hline Generous nose/bulbous nasal tip ${ }^{a}$ & $58 \%$ & $42 \%$ & \\
\hline Recessed forhead & $55 \%$ & $45 \%$ & \\
\hline Prominent supraorbital ridges & $55 \%$ & $45 \%$ & \\
\hline Full lips ${ }^{a}$ & $50 \%$ & $50 \%$ & \\
\hline Prominent nasal bridge & $50 \%$ & $50 \%$ & 3 \\
\hline Broad alar base $^{a}$ & $36 \%$ & $63 \%$ & \\
\hline Coarse features $^{a}$ & $29 \%$ & $71 \%$ & 3 \\
\hline Posteriorly rotated ears & $11 \%$ & $89 \%$ & 3 \\
\hline Prognathism & $5 \%$ & $95 \%$ & 38 \\
\hline Broad fingertips $^{a}$ & $58 \%$ & $42 \%$ & 3 \\
\hline Short fingers ${ }^{a}$ & $43 \%$ & $57 \%$ & 37 \\
\hline Prominent superficial vessels (hands) & $30 \%$ & $74 \%$ & 37 \\
\hline $5^{\text {th }}$ digit brachydactyly & $14 \%$ & $86 \%$ & 37 \\
\hline $5^{\text {th }}$ digit clinodactyly & $3 \%$ & $97 \%$ & 37 \\
\hline Narrow AP chest diameter ${ }^{a}$ & $74 \%$ & $26 \%$ & 23 \\
\hline
\end{tabular}

The prevalences are given in median percentage of $\mathrm{N}$ patients. The presence or absence of a trait was independently scored by a panel of three clinical geneticists.

${ }^{a}$ Core features as suggested by the principle component analysis in the dendrogram (Figure 2) are printed in italics. 
ing missing values in the calculation) are presented. All statistical analyses were performed in R (http://www.r-project. org/). Each feature was categorically rated as absent (0) or present (1). Missing values were imputed using multiple imputations and predictive mean matching using the Hmisc package (Frank Harrell, Department of Biostatistics, Vanderbilt University, USA). Internal consistency of the measurements, representing the correlations among the items, was assessed with Cronbach's alpha. ${ }^{24} \mathrm{~A}$ high value for alpha would indicate that the features internally correlate with each other which is a measure for reliability of a scale.

Statistical overlap of the clinical features was examined using principle component analysis (PCA). PCA is a technique that reduces a given number of possibly correlated variables into principle components, i.e., a smaller number of core variables, by data reduction and structure detection. The data were clustered allowing the grouping of the clinical features into statistically similar subgroups (divisive algorithms, Euclidian metric). This allowed the overlap found in the principal component analysis to be appreciated in terms of probable Fabry clinical features. This cluster analysis minimizes variation across patients and raters within dysmorphology feature sets and maximizes differences between dysmorphology feature groups (sets) across patients and raters. Agreement between observers was examined using Light's kappa globally for n-raters and Cohen's kappa for pair-wise comparison between the individual raters. ${ }^{25,26}$ This provided a chance-adjusted measure of inter-rater agreement. In general, Kappa values range between -1.00 indicating perfect disagreement and 1.00 indicating perfect agreement between the raters. A kappa of zero implies no agreement beyond chance. The level of agreement has been categorized into "poor" (kappa $<0.20)$, "fair" (kappa between 0.21 and 0.40) "moderate" (kappa between 0.41 and 0.60), "good" (kappa between 0.61 and 0.80) and "excellent" (kappa between 0.81 and 1.00). ${ }^{27}$

\section{RESULTS}

In this cohort of 38 patients with Fabry disease we identified dysmorphologic features as shown in Table 1 and Figures 1-4. There was a high internal consistency of these variables (Cronbach's alpha $=0.62$ ) on the 38 complete sample sets of pa-
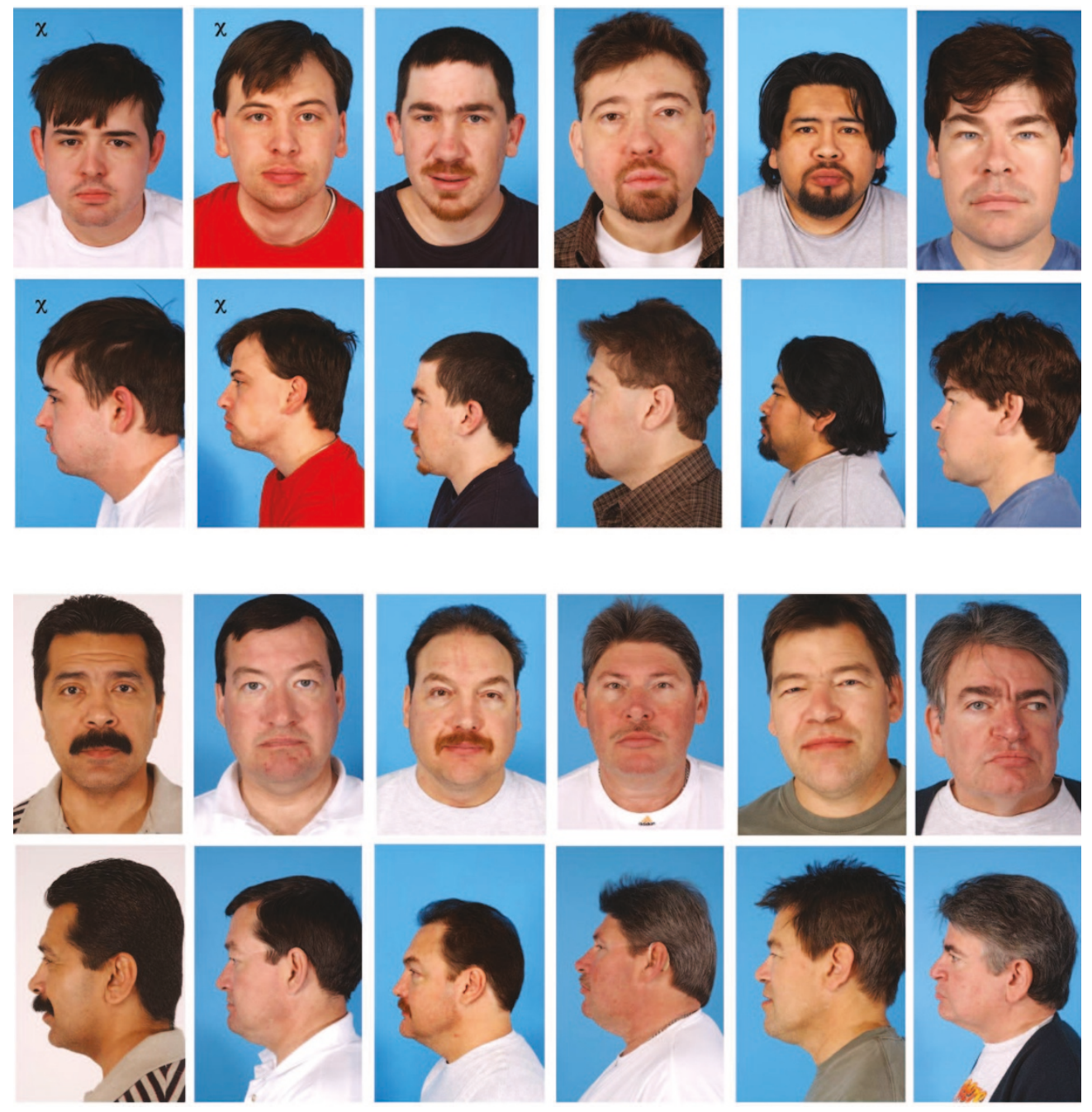

Fig. 1. Facial images of patients with Fabry disease with frontal face directly above profile view of the same patient arranged from youngest to oldest. $\chi$ denotes cousins. 
A

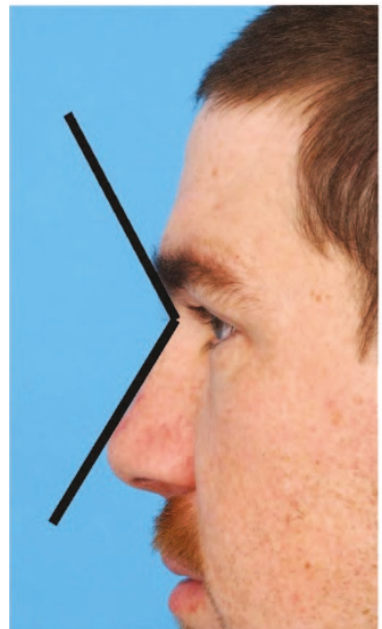

B

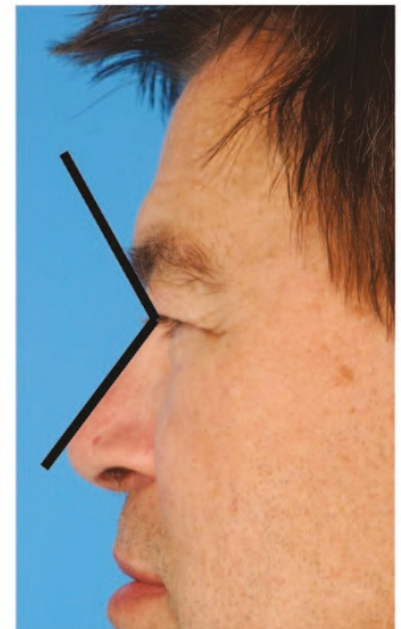

C

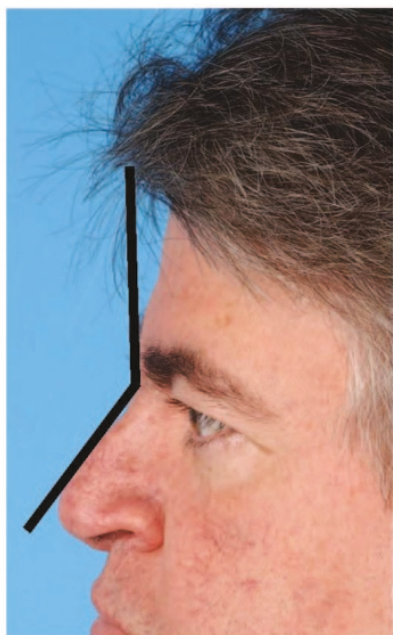

Fig. 2. Nasal angle, described as the angle between the nasal bridge and the nasal root, arranged (A, B) pronounced nasal angle, (C) normal.

A

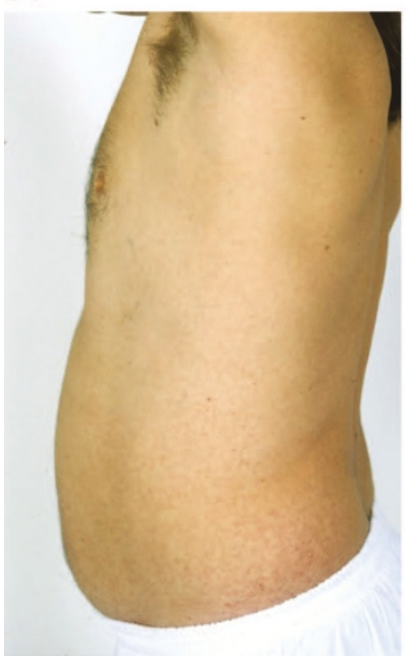

C

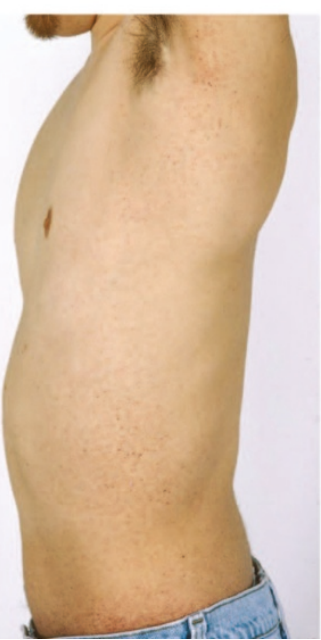

Fig. 3. Composite of AP chest photos: A) normal AP chest diameter; B-D) narrow AP chest diameter.
B

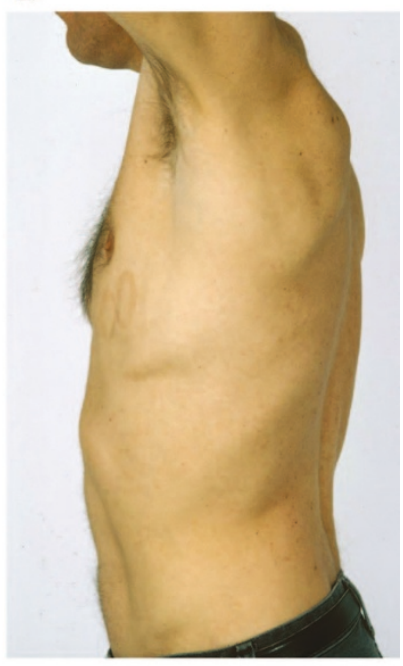

D

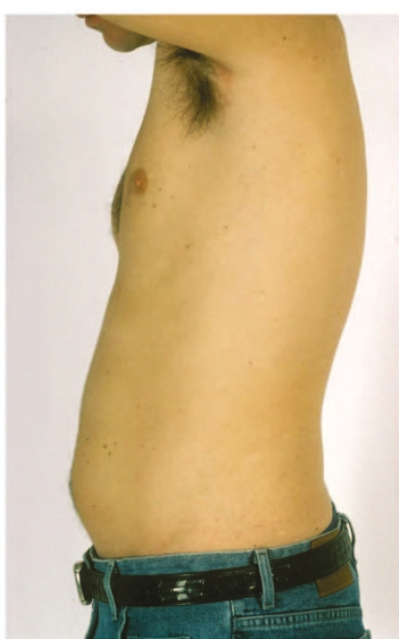

A

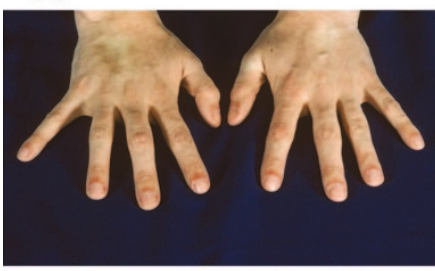

C

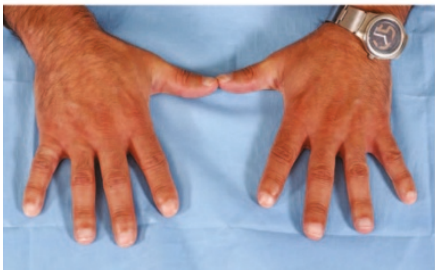

B

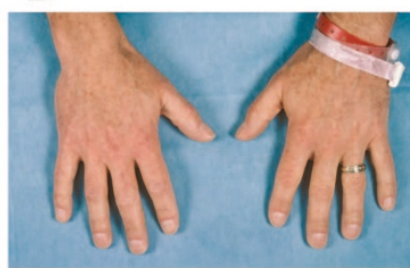

D

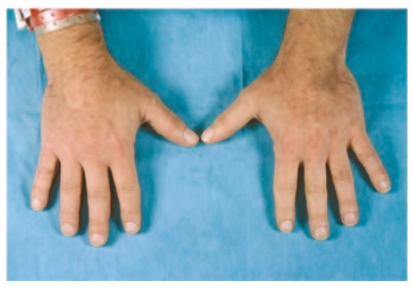

Fig. 4. Digital findings: A) normal; B-D) illustrate short fingers and broad fingertips.

tients. After principal component analysis (PCA) the initial 20 -feature set was statistically reduced to the number of independent features supported by the data set. The statistical dimensionality of the data set determined by PCA suggested a core of $\sim 10$ features. Cronbach's alpha for the imputed data set was 0.69 (sample size 38 patients, imputation for missing values $4.1 \%$ ). Light's kappa for n-observer inter-rater-variability was 0.27 while Cohen's kappa allowing pair-wise rater comparison varied between $0.08-0.48$. Clinical feature clustering is presented in Figure 5.

\section{DISCUSSION}

In this cross-sectional study of unselected 38 patients with Fabry disease characteristic facial features were identified. These features which included periorbital fullness, prominent lobules of the ears, bushy eyebrows, recessed forehead, pronounced nasal angle, generous nose/bulbous nasal tip, prom- 


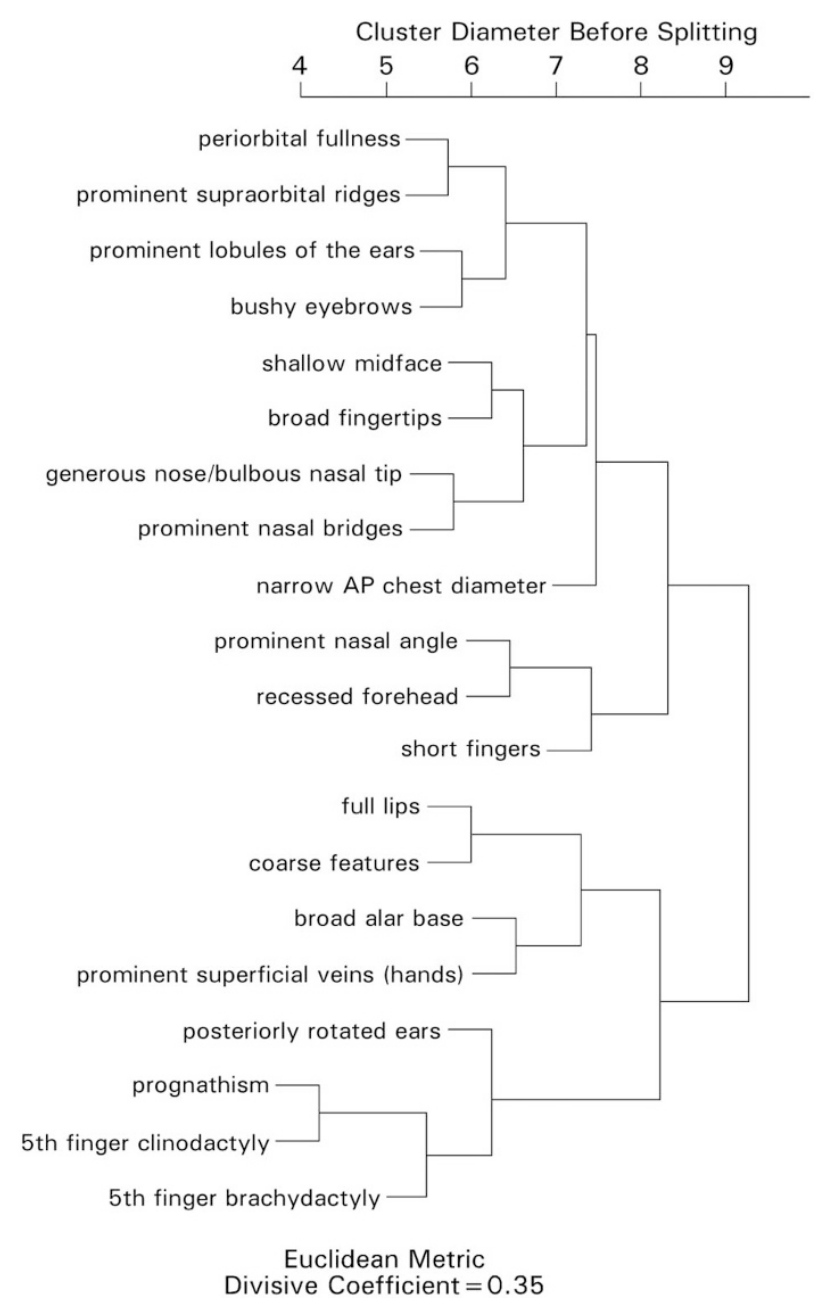

Fig. 5. Cluster diagram as derived by the principle component analysis of the Fabry dysmorphology dataset illustrating the closely associated clinical features. Clustering was performed using a divisive algorithm. This dendrogram allows the identification of core features taking into account the clustering, the 10 independent items of the principle component analysis and the prevalence as specified in Table 1.

inent supraorbital ridges, shallow midface, full lips, prominent nasal bridge, broad alar base, and coarse features define a distinctive facial appearance, recognizable by an astute observer. Statistical analysis defined $\sim 10$ of these dysmorphic characteristics as core features. It is also likely that these features become more pronounced over time as expected with storage processes. Patients with detectable residual $\alpha$-galactosidase A enzyme activity have less pronounced features (data not shown). Ethnicity may also be a variable that contributes to the dysmorphic appearance. There was no single defining trait. In isolation, some of these features are subtle which may account for the lower inter-rater variability. Coarse facial features are relatively common in other lysosomal storage disorders such as mucopolysaccharidosis, ${ }^{28} \mathrm{GM}_{1}$-gangiosidosis, ${ }^{29}$ Sandhoff disease, ${ }^{30,31}$ pycnodysostosis, ${ }^{32}$ aspartylglucosaminuria, ${ }^{33} \mathrm{mu}-$ colipidosis II, ${ }^{34}$ alpha-mannosidosis, ${ }^{35}$ beta-mannosidosis, ${ }^{36,37}$ fucosidosis,$^{38}$ sialidosis, ${ }^{39}$ and galactosialidosis,${ }^{40}$ however, this was only observed in $29 \%$ of this cohort of patients with Fabry disease. The facial features, such as recessed forehead, promi- nent nasal angle, and prominent supraorbital ridges described in these studies are distinctive from coarse facies seen in other storage disorders. The precise mechanism of development of these features is not known. For example, alpha-D-galactose glycoconjugates may accumulate in connective tissue and disturb its structure and metabolism. This has been reported in heart valves, ${ }^{41}$ bone, ${ }^{42}$ lens, ${ }^{43}$ lymphatic vessels, ${ }^{44}$ and fibroblasts. ${ }^{7}$ Cysts and pseudocysts of the maxillary sinus were also observed consistent with bony involvement that may also contribute to the facies. ${ }^{45} \mathrm{~A}$ blinded analysis of images comparing the status of the dysmorphic features at baseline and after four years of enzyme replacement therapy showed no difference ( $N$ $=22$ ).

The present paper has several limitations. While this is the largest cohort of patients with Fabry disease ever studied for morphologic features, the number of patients in this study is limited due to the rarity of the condition. Secondly, the patients who were referred to the NIH Clinical Center - which is a research facility - may not represent the total population. On the other hand, these patients were not selected for the variables evaluated. Thirdly, there is no control group in this study, and data concerning the prevalence of these features in the general population are not available.

\section{CONCLUSIONS}

The knowledge and recognition of the anthropometric features described above may facilitate the identification and diagnosis of patients with Fabry disease and their affected family members leading to earlier diagnosis and treatment. Our statistical approach can be applied in the assessment of dysmorphology in other diseases or syndromes.

\section{ACKNOWLEDGMENTS}

We are indebted to our patients for their participation in this study, to Cheryl Hipple for patient care coordination and to Meryl Poland for administrative assistance. This work was supported by the Intramural Program of the National Institutes of Neurological Disorders and Stroke.

\section{References}

1. Fabry J. Ein Beitrag zur Kenntnis der Purpura haemorrhagica nodularis (Purpura papulosa haemorragica Hebrae). Arch Dermatol Syphilis 1898;43:187-200.

2. Anderson W. A case of angiokeratoma. Br J Dermatol 1898;18:113-117.

3. Brady RO, Gal AE, Bradley RM, Martensson E, Warshaw AL, Laster L. Enzymatic defect in Fabry's disease. Ceramidetrihexosidase deficiency. N Engl J Med 1967;276: 1163-1167.

4. Gadoth N, Sandbank U. Involvement of dorsal root ganglia in Fabry's disease. J Med Genet 1983;20:309-312.

5. O'Brien BD, Shnitka TK, McDougall R, Walker K, Costopoulos L, Lentle B, Anholt L, Freeman H, Thomson AB. Pathophysiologic and ultrastructural basis for intestinal symptoms in Fabry's disease. Gastroenterology 1982;82:957-962.

6. Klug H, Zabel R, Evers U. [Fabry disease: clinical, biochemical and electron microscopical studies (author's transl)]. Dermatol Monatsschr 1979;165:46-54.

7. Tsukada N, Hanu N, Oguchi K, Yanagisawa N, Tsukagoshi H, Hattori H. [Fabry's disease with malocclusion and acromegalic-appearance: clinical and electromicroscopic studies (author's transl)]. No To Shinkei 1980;32:311-319.

8. Le Charpentier Y, Crouzet J, Le Charpentier M, Lessana-Leibowitch M, Di Crescenzo MC, Bennett B, Abelanet R. [Fabry's disease without cutaneous angiok- 
eratoma : diagnosis by electron microscope study of skin biopsy (author's transl)]. Semin Hop 1981;57:78-82.

9. Alroy J, Sabnis S, Kopp JB. Renal pathology in Fabry disease. J Am Soc Nephrol 2002;13:S134-S138.

10. Sessa A, Toson A, Nebuloni M, Pallotti F, Giordano F, Battini G, Maglio A, Meroni M, Calconi G, Bertolone G, Gatti P. Renal ultrastructural findings in AndersonFabry disease. J Nephrol 2002;15:109-112.

11. Ries M, Gupta S, Moore DF, Sachdev V, Quirk JM, Murray GJ, Rosing DR, Robinson C, Schaefer E, Gal A, Dambrosia JM, Garman SC, Brady RO, Schiffmann R. Pediatric Fabry disease. Pediatrics 2005;115:e344-355.

12. Ries M, Ramaswami U, Parini R, Lindblad B, Whybra C, Willers I, Gal A, Beck M. The early clinical phenotype of Fabry disease: a study on 35 European children and adolescents. Eur J Pediatr 2003;162:767-772.

13. Kampmann C, Baehner F, Ries M, Beck M. Cardiac involvement in Anderson-Fabry disease. J Am Soc Nephrol 2002;13:S147-149.

14. Branton MH, Schiffmann R, Sabnis SG, Murray GJ, Quirk JM, Altarescu G, Goldfarb L, Brady RO, Balow JE, Austin Iii HA, Kopp JB. Natural history of Fabry renal disease: influence of alpha-galactosidase A activity and genetic mutations on clinical course. Medicine (Baltimore) 2002;81:122-138.

15. Crutchfield KE, Patronas NJ, Dambrosia JM, Frei KP, Banerjee TK, Barton NW, Schiffmann R. Quantitative analysis of cerebral vasculopathy in patients with Fabry disease. Neurology 1998;50:1746-1749.

16. Schiffmann R, Kopp JB, Austin HA, 3rd, Sabnis S, Moore DF, Weibel T, Balow JE, Brady RO. Enzyme replacement therapy in Fabry disease: a randomized controlled trial. JAMA 2001;285:2743-2749.

17. Eng CM, Guffon N, Wilcox WR, Germain DP, Lee P, Waldek S, Caplan L, Linthorst GE, Desnick RJ. Safety and efficacy of recombinant human alpha-galactosidase A-replacement therapy in Fabry's disease. N Engl J Med 2001;345:9-16.

18. Schiffmann R, Floeter MK, Dambrosia JM, Gupta S, Moore DF, Sharabi Y, Khurana RK, Brady RO. Enzyme replacement therapy improves peripheral nerve and sweat function in Fabry disease. Muscle Nerve 2003;28:703-710.

19. Wilcox WR, Banikazemi M, Guffon N, Waldek S, Lee P, Linthorst GE, Desnick RJ, Germain DP. Long-term safety and efficacy of enzyme replacement therapy for Fabry disease. Am J Hum Genet 2004;75:65-74.

20. Beck M, Ricci R, Widmer U, Dehout F, de Lorenzo AG, Kampmann C, Linhart A, Sunder-Plassmann G, Houge G, Ramaswami U, Gal A, Mehta A. Fabry disease: overall effects of agalsidase alfa treatment. Eur J Clin Invest 2004;34:838-844.

21. MacDermot KD, Holmes A, Miners AH. Anderson-Fabry disease: clinical manifestations and impact of disease in a cohort of 98 hemizygous males. J Med Genet 2001;38:750-760.

22. Whybra C, Kampmann C, Krummenauer F, Ries M, Mengel E, Miebach E, Baehner F, Kim K, Bajbouj M, Schwarting A, Gal A, Beck M. The Mainz Severity Score Index: a new instrument for quantifying the Anderson-Fabry disease phenotype, and the response of patients to enzyme replacement therapy. Clin Genet 2004;65:299-307.

23. Nayler JR. Clinical photography: a guide for the clinician. J Postgrad Med 2003;49: 256-262.

24. Nunnally JC, Bernstein IH. Psychometric Theory. 3rd ed. New York: McGraw-Hill; 1994:248-292.

25. Conger AJ. Integration and generalisation of Kappas for multiple raters. Psychological Bulletin 1980;88:322-328.

26. Cohen J. A coefficient of agreement for nominal scales. Educational and Psychological Measurements 1960;20:37-46.
27. Altman DG. Practical statistics for medical research. London: Chapman \& Hall; 1991: 397-439.

28. Cohen MM, Jr. Syndromology: an updated conceptual overview. VI. Molecular and biochemical aspects of dysmorphology. Int J Oral Maxillofac Surg 1989;18:339-346.

29. Landing BH, Silverman FN, Craig JM, Jacoby MD, Lahey ME, Chadwick DL. Familial Neurovisceral Lipidosis. An Analysis of Eight Cases of a Syndrome Previously Reported as "Hurler-Variant," "Pseudo-Hurler," and "Tay-Sachs Disease with Visceral Involvement”. Am J Dis Child 1964;108:503-522.

30. Sandhoff K, Andreae U, Jatzkewitz H. Deficient hexosaminidase activity in an exceptional case of Tay-Sachs disease with additional storage of kidney globoside in visceral organs. Life Sci 1968;7:283-288.

31. Krivit W, Desnick RJ, Lee J, Moller J, Wright F, Sweeley CC, Snyder PD, Jr., Sharp HL. Generalized accumulation of neutral glycosphingolipids with GM2 ganglioside accumulation in the brain. Sandhoff's disease (variant of Tay-Sachs disease). Am J Med 1972;52:763-770.

32. Maroteaux P, Lamy M. La pycnodysostose. Presse Med 1962;70:999-1002.

33. Palo J, Santavuori P, Haltia M. Recent findings on some "new" neurometabolic diseases. Riv Patol Nerv Ment 1976;97:191-198.

34. Beck M, Barone R, Hoffmann R, Kratzer W, Rakowsky T, Nigro F, Fiumara A. Interand intrafamilial variability in mucolipidosis II (I-cell disease). Clin Genet 1995;47: 191-199.

35. Ockerman PA. A generalized storage disorder resembling Hurler's syndrome. Lancet 1967;II:239-241.

36. Cooper A, Sardharwalla IB, Roberts MM. Human beta-mannosidase deficiency N Engl J Med 1986;315:1231.

37. Wenger DA, Sujansky E, Fennessey PV, Thompson JN. Human beta-mannosidase deficiency. N Engl J Med 1986;315:12011205.

38. Van Hoof F, Hers HG. Mucopolysaccharidosis by absence of alpha-fucosidase. Lancet 1968;1:1198.

39. Spranger J, Gehler J, Cantz M. Mucolipidosis I-a sialidosis. Am J Med Genet 1977;1: 21-29.

40. Goldberg MF, Cotlier E, Fichenscher LG, Kenyon K, Enat R, Borowsky SA. Macular cherry-red spot, corneal clouding, and -galactosidase deficiency. Clinical, biochemical, and electron microscopic study of a new autosomal recessive storage disease. Arch Intern Med 1971;128:387-398.

41. Desnick RJ, Blieden LC, Sharp HL, Hofschire PJ, Moller JH. Cardiac valvular anomalies in Fabry disease. Clinical, morphologic, and biochemical studies. Circulation 1976;54:818-825.

42. Horiuchi H, Saito N, Kobayashi S, Ota H, Taketomi T, Takaoka K. Avascular necrosis of the femoral head in a patient with Fabry's disease: identification of ceramide trihexoside in the bone by delayed-extraction matrix-assisted laser desorption ionization-time-of-flight mass spectrometry. Arthritis Rheum 2002;46:19221925.

43. Sher NA, Letson RD, Desnick RJ. The ocular manifestations in Fabry's disease. Arch Ophthalmol 1979;97:671-676.

44. Gemignani F, Pietrini V, Tagliavini F, Lechi A, Neri TM, Asinari A, Savi M. Fabry's disease with familial lymphedema of the lower limbs. Case report and family study. Eur Neurol 1979;18:84-90.

45. Baccaglini L, Schiffmann R, Brennan MT, Lancaster HE, Jr., Kulkarni AB, Brahim JS. Oral and craniofacial findings in Fabry's disease: a report of 13 patients. Oral Surg Oral Med Oral Pathol Oral Radiol Endod 2001;92:415-419. 